Article

\title{
Elements of the Endomucin Extracellular Domain Essential for VEGF-Induced VEGFR2 Activity
}

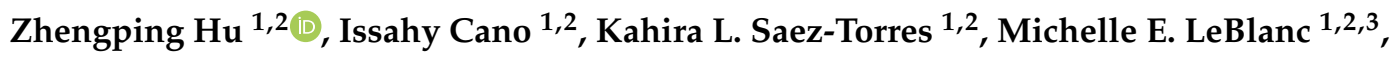 \\ Magali Saint-Geniez ${ }^{1,2}$, Yin-Shan $\mathrm{Ng}^{1,2}{ }^{\mathbb{D}}$, Pablo Argüeso ${ }^{1,2}\left(\mathbb{D}\right.$ and Patricia A. D'Amore ${ }^{1,2,4, *}$ \\ 1 Schepens Eye Research Institute of Massachusetts Eye and Ear, Boston, MA 02114, USA; \\ zhengping_hu@meei.harvard.edu (Z.H.); Issahy_Cano@MEEI.HARVARD.EDU (I.C.); \\ Kahira_Saez-Torres@MEEI.HARVARD.EDU (K.L.S.-T.); meleblan@gmail.com (M.E.L.); \\ Magali_Saintgeniez@MEEI.HARVARD.EDU (M.S.-G.); Eric_Ng@MEEI.HARVARD.EDU (Y.-S.N.); \\ Pablo_Argueso@MEEI.HARVARD.EDU (P.A.) \\ 2 Department of Ophthalmology, Harvard Medical School, Boston, MA 02114, USA \\ 3 Generation Bio, Cambridge, MA 02142, USA \\ 4 Department of Pathology, Harvard Medical School, Boston, MA 02115, USA \\ * Correspondence: patricia_damore@meei.harvard.edu
}

Received: 13 April 2020; Accepted: 1 June 2020; Published: 5 June 2020

\begin{abstract}
Endomucin (EMCN) is the type I transmembrane glycoprotein, mucin-like component of the endothelial cell glycocalyx. We have previously shown that EMCN is necessary for vascular endothelial growth factor (VEGF)-induced VEGF receptor 2 (VEGFR2) internalization and downstream signaling. To explore the structural components of EMCN that are necessary for its function and the molecular mechanism of EMCN in VEGF-induced endothelial functions, we generated a series of mouse EMCN truncation mutants and examined their ability to rescue VEGF-induced endothelial functions in human primary endothelial cells (EC) in which endogenous EMCN had been knocked down using siRNA. Expression of the mouse full-length EMCN (FL EMCN) and the extracellular domain truncation mutants $\triangle 21-81$ EMCN and $\Delta 21-121$ EMCN, but not the shortest mutant $\Delta 21-161$ EMCN, successfully rescued the VEGF-induced EC migration, tube formation, and proliferation. $\triangle 21-161$ EMCN failed to interact with VEGFR2 and did not facilitate VEGFR2 internalization. Deletion of COSMC (C1GalT1C1) revealed that the abundant mucin-type O-glycans were not required for its VEGFR2-related functions. Mutation of the two N-glycosylation sites on $\triangle 21-121$ EMCN abolished its interaction with VEGFR2 and its function in VEGFR2 internalization. These results reveal $\Delta 21-121$ EMCN as the minimal extracellular domain sufficient for VEGFR2-mediated endothelial function and demonstrate an important role for $N$-glycosylation in VEGFR2 interaction, internalization, and angiogenic activity.
\end{abstract}

Keywords: EMCN; glycosylation; angiogenesis; VEGF; VEGFR2; mucin

\section{Introduction}

Angiogenesis, the process by which new blood vessels arise from existing venules through budding and sprouting, plays an essential role in growth and development, wound healing, and repairing as well as in numerous physiological conditions [1]. In addition, angiogenesis is a hallmark of many pathogenic processes including tumor growth and metastasis, chronic inflammation, and a number of ocular pathologies [2,3]. While several factors are involved in the regulation of new blood vessel growth, vascular endothelial growth factor A (VEGF) has been shown to play a central role. Among the three tyrosine kinase receptors for VEGF, VEGF receptor 1 (VEGFR1), 2 (VEGFR2), and 3 (VEGFR3), VEGFR2 is the receptor that mediates a majority of VEGF's biological actions. 
VEGF binding to VEGFR2 initiates the formation of a multiprotein complex that includes VEGFR2 co-receptors [4], like neuropilin (NRP) and heparan sulfate proteoglycans (HSPGs), as well as integrins and endoglin [5]. Of all these associated proteins, the role of neuropilin in VEGFR2 signaling has been the best characterized. Upon VEGF binding, VEGFR2 homodimerizes and is phosphorylated on multiple tyrosine residues (Y951, Y1175, Y1059, and Y1214). Consequently, a number of signaling cascades are activated to mediate proliferation, migration, tube formation, and permeability, among other activities [6]. Activated VEGFR2 complexes with NRP1 and then is internalized through endocytosis [7]. The presence of the PDZ-binding domain of Nrp1 guides the internalized VEGFR2 to the Rab5/Rab11 pathway [8,9]. There is also evidence that VEGFR2 can be internalized through macropinocytosis [10]. Internalized VEGFR2 is either recycled back to the plasma membrane through fast or slow recycling pathways or is shuttled to lysosomes for degradation [11]. VEGF signaling is tightly regulated at all of these levels, including by receptor expression, by interactions with co-receptors or auxiliary proteins, and by the rate of internalization. For example, SCUBE2 (signal peptide-CUB-EGF domain-containing protein 2), CD146, basigin (CD147), and the urokinase plasminogen activator receptor (uPAR) [12-15] directly interact with VEGFR2 and regulate its activation, signaling, and functions. Small GTPase ARF6 controls VEGFR2 signal output via modulating its trafficking. Guanine nucleotide exchange factors (GEF) ARNO and GEP100 activate ARF6 independently. VEGFR2 interaction with ARNO activates ARF6 and stimulates VEGFR2 internalization, whereas interaction between VEGFR2 and GEP100 promotes VEGFR2 recycling via coreceptor binding. Intervening in either pathway inhibits VEGFR2 signal output [16].

The endothelial glycocalyx, which is comprised of proteoglycans and glycoproteins, extends from the luminal surface of vascular endothelium. The glycocalyx functions in cell-cell recognition, communication, and adhesion, and has been shown to play a role in various aspects of vascular homeostasis [17] and endothelial functions [18-21]. Glycosylation is one of the most common posttranslational modifications of proteins in general and of glycocalyx proteins in particular, and glycosylated proteins have been shown to play an important role in angiogenesis [14,22]. For instance, disruption of $\alpha 2$,6-sialylation leads to the loss of PECAM-VEGFR2 complexes, increases VEGFR2 internalization and VEGFR-dependent signaling, and impairs tumor angiogenesis through enhanced endothelial apoptosis [23]. Mucins, heavily glycosylated proteins with extended conformations, are important components of the glycocalyx [24] and have been shown to be involved in signal transduction by interacting with growth factor receptors or extracellular domain-mediated ligand binding $[25,26]$. Moreover, recent research indicates that mucins can strongly influence the shape and protrusions of the plasma membrane, thus having broad consequences on membrane processes, ranging from absorption and secretion to cellular communication, signaling, and motility [27].

Endomucin (EMCN) is a type I integral membrane glycoprotein expressed apically by capillary and venous endothelial cells (ECs). EMCN consists of 261 amino acids with an extracellular domain (ECD) that is highly $O$-glycosylated at serine and threonine residues and has several potential $\mathrm{N}$-glycosylation sites. The $\mathrm{O}$-glycans that are attached to these residues lead to a highly extended and rigid ECD. We have shown that EMCN interacts with VEGFR2 and regulates VEGFR2 internalization and its subsequent signaling [21]. In this study, we examined the structural elements of EMCN that are necessary for VEGF-induced VEGFR2 signaling. We have defined the minimum length of the EMCN ECD that interacts with VEGFR2 and is sufficient for its internalization. Moreover, we characterized the contribution of $O$-glycans and $N$-glycans on EMCN's ECD in VEGF-induced endothelium functions.

\section{Materials and Methods}

\subsection{Cell Culture}

Primary human retinal endothelial cells (HRECs) P3 were purchased from Cell Systems (ACBRI 181). HRECs were used within passages five through ten. HRECs were cultured on dishes pre-coated with $0.2 \%$ gelatin in phosphate-buffered saline (PBS) for $30 \mathrm{~min}$ at $37{ }^{\circ} \mathrm{C}$ in EGM-2 BulletKit 
medium (Lonza, Basel, Switzerland, \#CC-3162) supplemented with $2 \%$ fetal bovine serum (FBS) (Atlanta Biologicals, Flowery Branch, GA, USA), 2 mM L-glutamine (Lonza, \#17-605E), and $100 \mathrm{U} / \mathrm{mL}$ penicillin-100 $\mu \mathrm{g} / \mathrm{mL}$ streptomycin (Lonza, \#17-602E). Cells were maintained at $37^{\circ} \mathrm{C}$ with $5 \% \mathrm{CO}_{2}$.

\subsection{Reagents}

Non-targeting control siRNA (siCtrl, \#D-001810-01-05) and siRNA directed against EMCN (siEMCN, \#L-015860-01-0005) were purchased as SMART pools (Dharmacon, Lafayette, CO, USA). Dharmafect 1 transfection reagent (Dharmacon, \#T-2001-02) was used for cell culture studies. VEGF165 (\#293-VE-010) was purchased from R\&D Systems (Minneapolis, MN, USA). Primaquine bisphosphate (PQB, \#160393-1G), paraformaldehyde (4\% PFA, VWR \#AAJ61899-AP), Tween-20 (\#X251-07), and Phosphatase inhibitor cocktail (\#4906845001) were purchased from Sigma (St Louis, MO, USA). Sulfo-NHS-SS-Biotin (1859385), DTSSP (21578), avidin agarose (\#S1258122), monomeric avidin agarose (\#20228), and D-Biotin (\#29129) were purchased from Life Technologies (Carlsbad, CA, USA). Laemmli's SDS Sample Buffer (\#BP-110R) was purchased from Boston Bio Products (Ashland, MA, USA). Lysis Buffer (\#9803S) and protease inhibitors (\#5871S) were purchased from Cell Signaling (Beverly, MA, USA). Plasmid and adenovirus of mouse-truncated mutants were ordered from VectorBuilder (Chicago, IL, USA). Basically, sequence of mEMCN FL, $\Delta 21-81, \Delta 21-121$, and $\Delta 21-161$ were cloned into PAdEasy vector with CMV promoter through SgrDl. A Myc tag and a mCherry tag were added to the $C$-terminal of the construct, and 3xGGGGS linker was inserted between the Myc tag and mCherry tag.

\section{3. siRNA Knockdown}

HRECs were seeded at 70\% confluence one day prior to siRNA transfection. siEMCN (50 nM, \#L-015860-01-000) or siCtrl (50 nM, \#D-001810-01-05) were incubated with Dharmafect 1 transfection reagent in OPTIMEM (Life Technologies, \#51985034) at room temperature for $30 \mathrm{~min}$ to allow complex formation. siRNA was added in EGM-2 complete media supplemented with $2 \%$ FBS in the absence of penicillin-streptomycin. The following day, culture media were changed and cells were incubated for an additional $24 \mathrm{~h}$ before experiments.

\subsection{Adenoviral Overexpression}

HRECs were seeded at 70\% confluence one day prior to adenoviral infection. Cells were infected with adenovirus expressing mEMCN mutants (AdmEMCN) at an multiplicity of infection (MOI) of 5 and cultured for $48 \mathrm{~h}$ in EGM-2 media supplemented with 2\% FBS (Atlanta Biologicals, Flower Branch, GA, USA, \#S11195). mCherry autofluorescence were examined using EVOS Cell Imaging System to evaluate the expression.

\subsection{Biotin Cell Surface Isolation}

Confluent HRECs were serum starved for $2 \mathrm{~h}$ in EBM-2 basal media. Cells were then stimulated with VEGF $(10 \mathrm{ng} / \mathrm{mL})$ in serum-free EBM-2 media supplemented with PQB $(0.6 \mu \mathrm{M})$. Cell surface proteins were biotinylated with NHS-SS-biotin (\#1859385) for $2 \mathrm{~h}$ at $4{ }^{\circ} \mathrm{C}$ and, then, quenched by

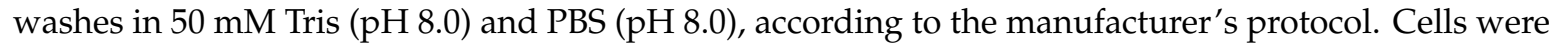
scraped into Tris-buffered saline (TBS) and collected by centrifugation at $1500 \times g$ for $5 \mathrm{~min}$. Pellets were lysed in Cell Signaling Lysis Buffer and incubated with $100 \mu \mathrm{L}$ of Avidin Agarose (\#S1258122) rotating for $1 \mathrm{~h}$ at room temperature. Samples were washed four times in Wash Buffer $(20 \mathrm{mM}$ Tris- $\mathrm{HCl}$, $\mathrm{pH} 6.8,0.5 \%$ Tween-20) with protease and phosphatase inhibitors and were centrifuged at $1000 \times g$ for $1 \mathrm{~min}$. Cell surface proteins were eluted with Laemmli's SDS Sample Buffer (\#BP-110R) with $100 \mathrm{mM}$ dithiothreitol (DTT), boiled at $95^{\circ} \mathrm{C}$ for $10 \mathrm{~min}$, and processed for western blot analysis. Membranes were incubated with antibodies against VEGFR2 (1:1,000, Cell Signaling \#55B11), hEMCN (1:300, \#ab45771), or mouse anti-CD31 (1:1,000, Cell Signaling \#89C2) as a loading control for cell surface fractions. Glyceraldehyde 3-phosphate dehydrogenase (GAPDH) or a-tubulin was used as loading 
control for whole cell lysate. For VEGFR2 internalization, the ratio of uninternalized VEGFR2 was calculated as VEGFR2 remaining on cell surface following VEGF stimulation divided by cell surface VEGFR2 in the unstimulated control. The ratio of internalized VEGFR2 equaled to 1 minus the ratio of uninternalized VEGFR2.

\subsection{Migration Assay}

HRECs were transduced with adenovirus expressing EMCN mutants at MOI 5 after reaching confluence in 12-well plate. siRNA targeting the endogenous EMCN with non-targeting siRNA as control was applied. HRECs were scratched using a P200 pipette tip $48 \mathrm{~h}$ after transfection. Cell debris was removed by washing with PBS. Serum-free EBM-2 basal medium (Lonza, \#CC-3162) with or without $10 \mathrm{ng} / \mathrm{mL}$ VEGF was added into each well. Images of the wound edges were taken using EVOS at time $0 \mathrm{~h}$ and $15 \mathrm{~h}$ after the scratch. Migration was quantified as the closure percentage in the wound area/time and averaged for two locations per well from a triplicate set of samples for each experimental condition. The images were analyzed using Image J (National Institutes of Health and the Laboratory for Optical and Computational Instrumentation).

\subsection{Cell Proliferation Assay}

HRECs were transduced with adenovirus overexpressing EMCN-truncated mutant and siRNA targeting EMCN or non-targeting siRNA as control. HRECs were seeded in 24 -well plates at $2 \times$ 104/well and serum-starved EBM-2 basal media (Lonza, \#CC-3162) $48 \mathrm{~h}$ after adenovirus transfection or were grown in serum-free EBM-2 basal medium (Lonza, \#CC-3162) with or without VEGF $(10 \mathrm{ng} / \mathrm{mL}$ ) and counted using a Coulter Counter every $24 \mathrm{~h}$.

\subsection{Tube Formation Assay}

Endogenous EMCN was knocked down using siRNA, and the overexpression of truncated mutants was achieved by adenoviral expression. Basement membrane extract (BME) ( $50 \mu \mathrm{L}$; Cultrex, Gaithersburg, MD, USA) was added into 96-well plates $30 \mathrm{~min}$ prior to the experiment and incubated in $37^{\circ} \mathrm{C}$ to solidify. Serum-starved HRECs were plated $\left(2 \times 10^{4}\right)$ and treated with or without $10 \mathrm{ng} / \mathrm{mL}$ VEGF. The total length of tubes and segments formed were quantified using Image J Angiogenesis Analyzer plug-in 3 to $6 \mathrm{~h}$ after VEGF stimulation.

\subsection{Immunoprecipitation}

HRECs were plated in 150-mm dishes at confluence in EGM-2 complete media supplemented with $2 \%$ FBS for $48-72 \mathrm{~h}$. Cells were scraped into PBS and collected by centrifugation at $1500 \times g$ for $5 \mathrm{~min}$. Pellets were washed with cold PBS and lysed in hypotonic lysis buffer (10 mM Tris pH 7.5, $1 \mathrm{mM}$ Ethylenediaminetetraacetic acid (EDTA), $1 \mathrm{mM} \mathrm{MgCl}_{2}$, and $1 \mathrm{mM} \mathrm{CaCl}_{2}$ ) with protease inhibitors, vortexed briefly to obtain a homogeneous cell suspension, and then centrifuged for $10 \mathrm{~min}$ at $16,000 \times g$ at $4{ }^{\circ} \mathrm{C}$. The supernatant containing cytosolic proteins was carefully removed, and solubilization buffer (50 mM Tris-HCL, $100 \mathrm{mM} \mathrm{NaCl}, 5 \mathrm{mM}$ EDTA, 0.5\% Triton-X 100, 0.5\% NP-40, pH 7.5) with protease inhibitors was added. Cell surface lysates were incubated with mouse anti-Myc (1:25, Cell Signaling \#9B11) and mouse IgG (Santa Cruz, Dallas, TX, USA, sc-2025) overnight rotating at $4{ }^{\circ} \mathrm{C}$. The following day, samples were centrifuged and beads were washed in lysis buffer followed by washes in PBS with 0.1\% Tween. Bound proteins were eluted by incubation with Laemmli's SDS Sample Buffer (\# BP-110R) with $100 \mathrm{mM}$ DTT, boiled at $95^{\circ} \mathrm{C}$ for $10 \mathrm{~min}$, and processed for western blot analysis. Membranes were incubated with antibodies against rabbit anti-human VEGFR2 (1:1,000; Cell Signaling \#55B11) and rabbit anti-Myc (1:1,000; \#2278S). VEGFR2 intensity was normalized to each of the corresponding mutants on beads, detected by Myc intensity, and then compared to that of the FL mEMCN. 


\subsection{Western Blot}

Cells were lysed with buffer containing protease inhibitors (Roche, Basel, Switzerland) and a phosphatase inhibitor cocktail (1:100, Sigma). Protein concentration was determined by the BCA (Bicinchoninic Acid) Protein Assay (Thermo Scientific, Waltham, MA, USA, \#23227). Proteins separated on SDS-PAGE gels were transferred to nitrocellulose membranes (VWR, \#27376-991) and then probed with appropriate antibodies. Membranes were incubated with appropriate secondary antibodies and developed by fluorescence LI-COR Odyssey (LI-COR). Equal loading and transfer were determined by re-probing the membranes for housekeeping proteins. Densitometry analyses were performed by Image J or using Image Studio 2.0 (LI-COR). Arbitrary units of fluorescence were converted to fold-change compared to the control.

\subsection{Immunocytochemistry-Based Internalization}

HRECs were serum starved for $2 \mathrm{~h}$ in EBM-2 media and incubated with goat anti-VEGFR2 (R\&D Systems, \#AF357) or rat anti-EMCN $\left(1: 200\right.$, ab45771) at $4{ }^{\circ} \mathrm{C}$ for $1 \mathrm{~h}$, followed by the addition of BSA or VEGF $(10 \mathrm{ng} / \mathrm{mL})$ for $30 \mathrm{~min}$ at $37^{\circ} \mathrm{C}$. Cells were fixed in $4 \%$ PFA for $5 \mathrm{~min}$ at room temperature and permeabilized using $0.1 \%$ Triton. Fluorescent secondary antibodies Alexa 594-labeled donkey anti-goat (1:300, Life Technologies, \#A-11058) and Alexa 488-labeled donkey anti-mouse (1:300, Life Technology, \#A-21202) were used for immunocytochemistry (ICC). All experiments were conducted in the presence of PQB $(0.6 \mu \mathrm{M})$ to prevent receptor recycling. Images of cells were taken using Zeiss Axioscope (Oberkochen, Germany). Intracellular fluorescence intensity was quantified using Adobe Photoshop CC (Adobe Inc., San Jose, CA, USA) and normalized to the total number of cells per viewing field, as an indication of receptor internalization. Five images per cover slip (two coverslips) were imaged, analyzed, and averaged. Quantification reflects three independent experiments.

\subsection{Genomic Deletion of COSMC}

Ribonucleoprotein delivery of CRISPR/Cas 9 was applied. The Gene Knockout Kit v2 from Synthego with three spatially coordinated synthetic sgRNAs targeting exon 2 of the COSMC gene was used to improve the knockout efficiency. Non-targeting was used as control. The sequences of sgRNAs were guide \#1 CUUCUUUGUUAGGAGCUUGU; guide \#2 GGACACAUUAGGAUUGGUCA; and guide \#3 GAAAGCAGCUCCUUUUUGAA. In brief, $3 \mu \mathrm{M}$ sgRNA and $20 \mu \mathrm{M}$ Cas 9 protein were introduced in HRECs through reverse transfection according to the Lipofectamine CRISPRMAX (Thermo Fisher, Waltham, MA, USA, CMAX00001) protocol.

\subsection{Enzymatic Removal of $\mathrm{N}$-glycans}

HRECs were infected with adenovirus expressing mEMCN mutants (AdFL, Ad $\triangle 21-81, \operatorname{Ad} \triangle 21-121$, and $\mathrm{Ad} \Delta 21-161)$ at an MOI of 5 and cultured for $48 \mathrm{~h}$ in EGM-2 media supplemented with $2 \%$ FBS (Atlanta Biologicals, \#S11195). Cells were scraped and pellet by centrifugation at $1000 \times g$ for 5 min using a table centrifuge. PNGase F (New England Biolabs, Ipswich, MA, USA, P0704S) digestion was performed as according to the manufacturer's instructions and analyzed by western blot. In brief, cells pellets were prepared from HRECs expressing mEMCN mutants and $1 \mu \mathrm{L}$ of PNGase F was added into $20 \mu \mathrm{L}$ denaturing reaction and incubated in $37^{\circ} \mathrm{C}$ for $1 \mathrm{~h}$ before western blot.

\subsection{Statistical Analysis}

All values are expressed as mean \pm SEM. Statistical analysis was performed using a 2-tail unpaired t-test or one-way ANOVA post hoc test (Prism 7, GraphPad Software Inc., San Diego, CA, USA). A $p$ value $<0.05$ was considered statistically significant. Each experimental condition was conducted in at least triplicate, and all experiments were independently repeated at least three times. 


\section{Results}

\section{1. $\triangle 21-121$ EMCN Rescues VEGF-Induced Functions in HREC Lacking Endogenous EMCN}

The ECD of EMCN is comprised of 190 amino acids. Constructs of mouse EMCN (mEMCN) with a full-length ECD (FL EMCN) and mutants with truncated ECD including full-length EMCN (FL EMCN), $\triangle 21-81$ EMCN, $\triangle 21-121 \mathrm{EMCN}$, and $\triangle 21-161 \mathrm{EMCN}$ were generated (Figure $1 \mathrm{~A}$ ) and include a signal peptide (SP, amino acids 1-20), a Myc tag, and a mCherry tag at the C-terminus. The efficiency of transduction was over $90 \%$ as examined by the autofluorescent signal of mCherry. DAPI ( $4^{\prime}, 6$-diamidino-2-phenylindole) was included to label the nuclei. Protein expression of the different mEMCN constructs was detected by mCherry autofluorescence in both the cytoplasm and on the cell surface (Figure 1B). Because all of the constructs included a signal sequence, we suspect the mEMCN mutants in the cytoplasm are largely localized to membranes, but resolution at the light microscopic level does not allow us to draw that conclusion. Biotinylation was used to further demonstrate cell surface protein expression of all the truncation mutants as well as to characterize the different mEMCN mutants (Figure 1C). The varying levels of cell surface expression for each mEMCN mutants is shown in Figure S1. FL EMCN, $\triangle 21-81$ EMCN, $\triangle 21-121 \mathrm{EMCN}$, and $\triangle 21-161 \mathrm{EMCN}$ were detected at the relative molecular weights of approximately $130 \mathrm{KDa}, 100 \mathrm{KDa}, 75 \mathrm{KDa}$, and $50 \mathrm{KDa}$, respectively.

In order to determine the minimum size of the EMCN ECD sufficient for VEGF-induced endothelial functions, endogenous human EMCN (hEMCN) in primary HRECs was knocked down using siRNA and individual mEMCN mutants were expressed via adenovirus transduction. The optimal time course for these studies was first determined by expressing FL EMCN. Cells were incubated for $24 \mathrm{~h}$ with the adenovirus, and the peak FL EMCN expression was detected 48 to $96 \mathrm{~h}$ post-transduction by immunostaining (Figure 1D). Neither the siRNA directed against the hEMCN nor the antibodies cross-react with mEMCN (Figure 1E). The expression of total endogenous hEMCN and FL EMCN (detected by its Myc tag) at different time points is shown in Figure 1E. Expression of endogenous hEMCN protein was suppressed by over $95 \%$ from 24 to $96 \mathrm{~h}$. Thus, studies were conducted under the knockdown of endogenous hEMCN and expression of the various mEMCN ECD truncation mutants as shown in Figure 1F.

We next determined if the different mEMCN mutants could rescue VEGF-induced migration, tube formation, and/or cell proliferation in HRECs lacking endogenous EMCN. As expected, compared to the siNT control, EMCN knockdown inhibited VEGF-stimulated cell migration and expression of the control mCherry construct did not rescue cell migration $(1.71 \pm 0.05$ versus $1.12 \pm 0.04, p<0.005)$. On the other hand, expression of FL EMCN, $\triangle 21-81$ EMCN, and $\triangle 21-121$ EMCN rescued cell migration following VEGF stimulation, compared to mCherry control $(1.7 \pm 0.04,1.43 \pm 0.08,1.46 \pm 0.96$, versus $1.12 \pm 0.04$, respectively, $p<0.05$ for all, $n=8$ ). In contrast, expression of $\Delta 21-161$ EMCN was unable to rescue VEGF-induced HREC migration (1.13 \pm 0.087 versus $1.12 \pm 0.04$ ) (Figure 2A,B).

The ability of the various mutants to rescue in vitro VEGF-induced tube formation assay was examined [27]. EMCN silencing inhibited both total tube formation and total segment formation (Figure 2C-E). Expression of FL EMCN, $\Delta 21-81$ EMCN, and $\Delta 21-121$ EMCN but not $\Delta 21-161$ EMCN restored VEGF-stimulated tube formation in HRECs compared to mCherry control (Figure 2C-E). Cell proliferation, another crucial component of angiogenesis, was examined by counting cell number $48 \mathrm{~h}$ post-VEGF stimulation. Consistent with previously observed cell functions, FL EMCN, $\triangle 21-81$ EMCN, and $\triangle 21-121$ EMCN expression also rescued cell proliferation whereas $\triangle 21-161 \mathrm{EMCN}$ expression did not (Figure $2 \mathrm{~F}$ ). 
A

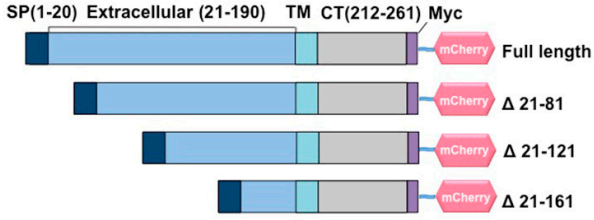

C

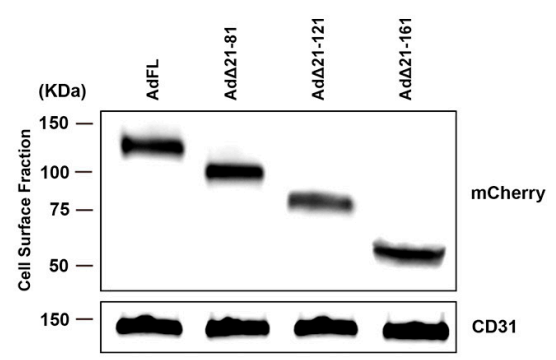

B



$72 \mathrm{~h}$

$120 \mathrm{~h}$

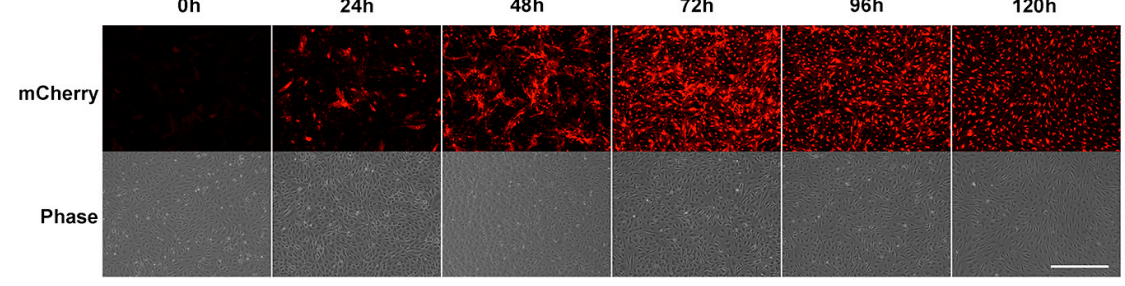

E

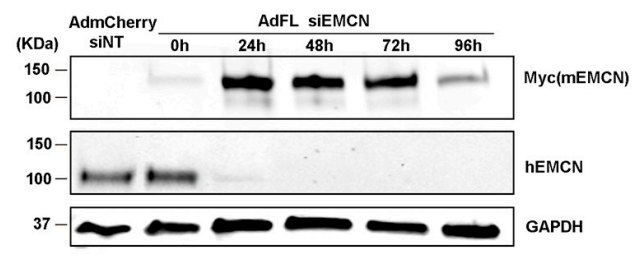

F

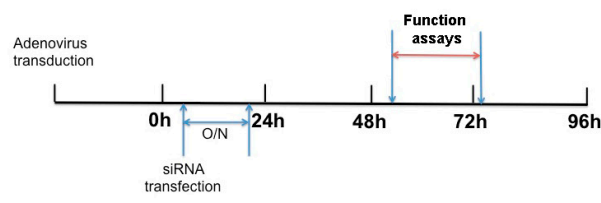

Figure 1. Endomucin (EMCN) mutants: constructs, expression, and experimental design. (A) Schematic representation of the full-length (FL) murine EMCN protein and the truncation mutants. SP, signal peptide; TM, transmembrane domain; CT, cytoplasmic tail; mCherry, fluorescence tag. (B) Human retinal endothelial cells (HRECs) were transduced overnight with adenoviruses expressing EMCN-truncated mutants. Autofluorescence of mCherry was examined $48 \mathrm{~h}$ post-infection. Scale bar: $100 \mathrm{um}$. Expression of all of the constructs was detected in the cytoplasm (indicated by yellow arrow) as well as on the cell surface (indicated by white arrow). (C) Adenoviruses expressing EMCN-truncated mutants were transduced into HRECs, and cell surface proteins were labeled by biotinylation and analyzed by western blot using antibodies against mCherry and CD31. The FL as well as all of the mutants were detected at the cell surface at the expected molecular weights. (D) HRECs were transduced with adenoviruses expressing EMCN truncated overnight, and mCherry fluorescence and phase contrast was examined every $24 \mathrm{~h}$. Scale bar: $200 \mu \mathrm{m}$ Expression was detected as early as $24 \mathrm{~h}$, peaked at $72 \mathrm{~h}$, and declined thereafter. (E) Cells lysates of HRECs in which endogenous hEMCN had been knocked down using siRNA and overexpressing full-length mouse EMCN was collected every $24 \mathrm{~h}$. and protein levels of Myc-tagged (Myc mEMCN) and hEMCN were examined by western blot. GAPDH was used as loading control. Endogenous hEMCN was effectively knocked down at 24-96 h whereas exogenously expressed mEMCN was highly expressed at 24-72 h. (F) Experimental design for subsequent studies shows that HRECs were transduced with adenoviruses overexpressing mEMCN mutants, and one day later, endogenous hEMCN was knocked down using siRNA. In vitro functional assays, vascular endothelial growth factor receptor 2 (VEGFR2) internalization and co-IP were conducted 48-72 h post-transfection. 
A

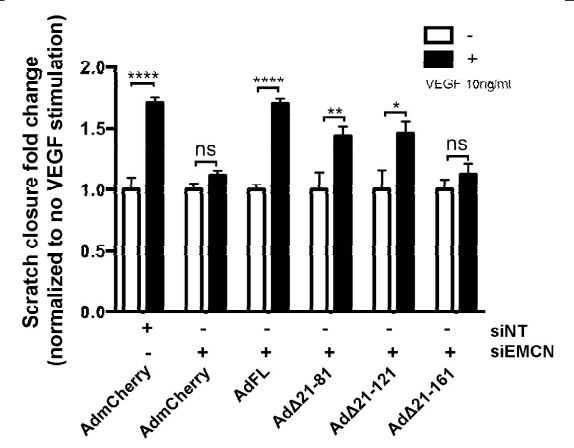

C

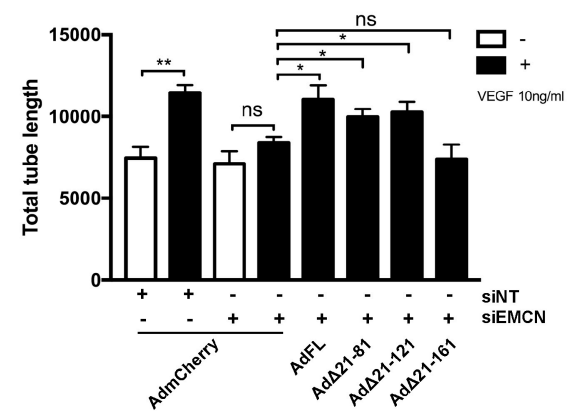

E

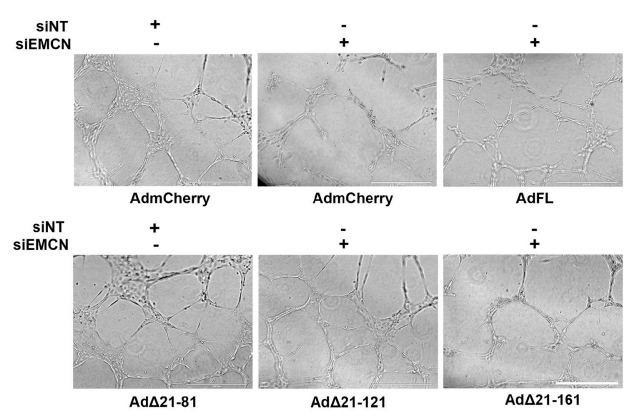

B

D
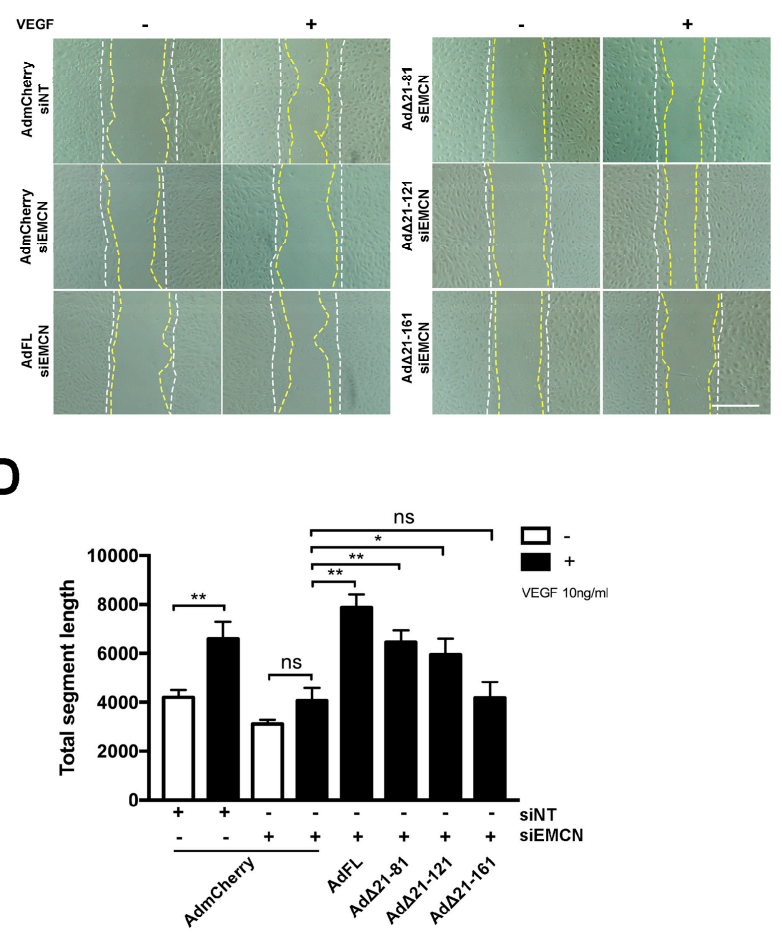

$F$

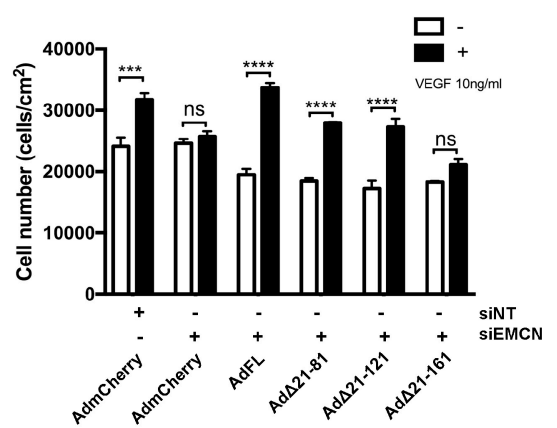

Figure 2. $\triangle 21-121 \mathrm{EMCN}$ is the minimal truncation mutant to rescue vascular endothelial growth factor (VEGF)-induced migration, tube formation, and cell proliferation of primary human endothelial cells. (A) HRECs were transduced with adenoviruses expressing the FL and different EMCN mutants individually, and endogenous hEMCN was knocked down using siRNA with non-targeting siRNA (siNT) as control. Then, VEGF-stimulated closure percentage was normalized to that without VEGF for each treatment group. EMCN knockdown abolished VEGF-induced migration, and $\triangle 21-161 \mathrm{EMCN}$ failed to rescue, unlike other mutants. (B) Representative images of cell migration: The white line indicates the initial wound area $(0 \mathrm{~h})$, and the yellow line marks the wound area after $15 \mathrm{~h}$. Plus and minus indicates the addition of VEGF. Scale bar: $100 \mathrm{um}$ (C,D) Tube formation by HREC at $6 \mathrm{~h}$ was recorded, and the total tube length and total segment length were quantified using Image J angiogenesis plug-in in a masked fashion. The FL EMCN, $\Delta 21-81$, and $\Delta 21-121$ all rescued VEGF-induced tube formation whereas $\Delta 21-161$ did not. (E) Representative images for the tube formation assay. Scale bar: $400 \mu \mathrm{m}$. (F) HRECs were incubated in serum-free media with and without $10 \mathrm{ng} / \mathrm{mL}$ VEGF and cell number following $48 \mathrm{~h}$ of incubation quantified. The FL EMCN, $\Delta 21-81$, and $\Delta 21-121$ all rescued VEGF-induced HREC proliferation whereas $\triangle 21-161$ did not. All data $=$ mean $\pm \mathrm{SEM}$, ns, not significant, ${ }^{*} p<0.05,{ }^{* *} p<0.01,{ }^{* * *} p<0.001$ and ${ }^{* * * *} p<0.0001$ by 2-tail unpaired t-test, $n \geq 3$. 


\section{2. $\triangle 21-161$ EMCN Does Not Interact With VEGFR2 or Rescue VEGFR2 Internalization}

VEGF mediates a majority of its effects through VEGFR2, and we have demonstrated that EMCN interacts with VEGFR2 and modulates its internalization [20]. The interaction of the different $\mathrm{mEMCN}$ mutants with VEGFR2 was examined by co-immunoprecipitation (co-IP) (Figure 3A), with FL EMCN and mCherry as positive and negative controls, respectively (Figure S2). The interaction of $\Delta 21-81$ EMCN and $\triangle 21-121$ EMCN with VEGFR2 was comparable to that for FL EMCN $(1.1 \pm 0.29,0.8 \pm 0.11$ vs $1.00 \pm 0.05$, respectively); however, VEGFR2 interaction with $\triangle 21-161 \mathrm{EMCN}$ was significantly reduced compared to FL EMCN $(0.01 \pm 0.0819$ vs $1.00 \pm 0.02, p<0.01)$ (Figure $3 \mathrm{~A}, \mathrm{~B}$ ).

A

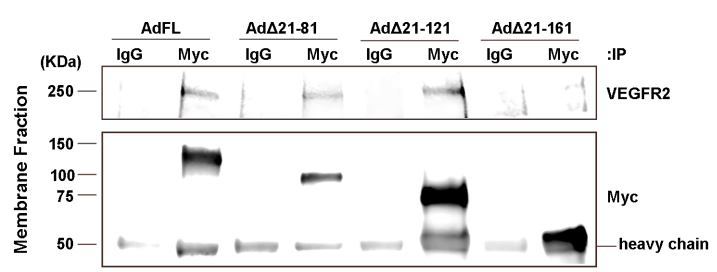

C

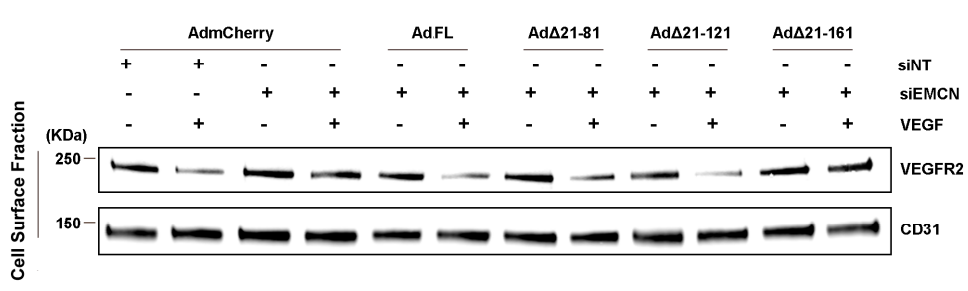

B
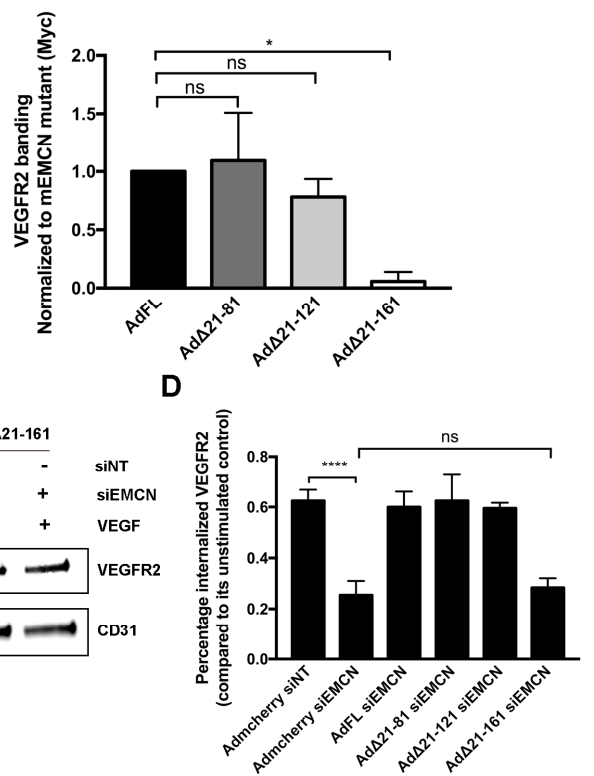

Figure 3. $\triangle 21-161$ EMCN does not interact with VEGFR2 or rescue VEGFR2 internalization. (A,B) Membrane proteins of HRECs lacking endogenous hEMCN and overexpressing the different Myc-tagged mEMCN constructs were extracted and subjected to co-immunoprecipitation (co-IP) using anti-Myc antibody, and the protein levels of VEGFR2 and the different mEMCN mutant proteins were examined by western blot. The FL EMCN, $\Delta 21-81$, and $\triangle 21-121$ all co-IP'ed with VEGFR2 whereas $\triangle$ 21-161 did not. (C,D) To assess VEGFR2 internalization, cell surface proteins were labeled using NHS-SS-biotin and isolated, and protein levels of VEGFR2 and CD31 were analyzed by western blot. The FL EMCN, $\Delta 21-81$, and $\Delta 21-121$ all rescued VEGFR2 internalization; $\Delta 21-161$ did not. All data $=$ mean \pm SEM, ns, not significant, ${ }^{*} p<0.05,{ }^{* * * *} p<0.0001$ by 2 -tail unpaired t-test, $n=4$.

Next, the effect of the various EMCN ECD mutants on VEGFR2 was examined. Cell surface expression of VEGFR2 following VEGF treatment was determined with NHS-SS biotin labeling and extraction using avidin beads (Figure 3C,D). EMCN knockdown suppressed VEGFR2 internalization compared to control $(0.25 \pm 0.03$ vs $0.62 \pm 0.025, p<0.001)$ (Figure 3C,D). Expression of FL EMCN, $\triangle 21-81$ EMCN, or $\triangle 21-121$ EMCN rescued VEGFR2 internalization in HRECs deficient in endogenous EMCN compared to mCherry control $(0.6 \pm 0.04,0.62 \pm 0.06,0.6 \pm 0.01$ vs $0.25 \pm 0.03$, respectively, $p<0.001$ for all). Consistent with its inability to rescue VEGF-induced cell migration and tube formation, $\triangle 21-161$ EMCN failed to rescue VEGFR2 internalization upon VEGF stimulation, compared to mCherry control $(0.28 \pm 0.02$ versus $0.25 \pm 0.03)$.

\subsection{O-Glycosylation of the EMCN ECD Is Not Necessary for VEGFR2 Internalization}

NetOGlyc 4.0 Server (http://www.cbs.dtu.dk/services/NetOGlyc/) predicts 57 potential O-glycosylation sites on hEMCN ECD and 58 O-glycosylation sites on mEMCN, with 63\% of the $O$-glycosylation sites overlapping. Thus, the ECD of EMCN is heavily O-glycosylated, whereas 
only five are predicted $\mathrm{N}$-glycosylation sites. To further investigate the structural elements involved in EMCN-VEGFR2 interaction, we examined how the role O-glycosylation in the ECD is involved in EMCN regulation of VEGFR2 signaling. COSMC (C1GALT1C1) is the unique and sole chaperone of T-synthase, which is the only enzyme that galactosylates the Tn antigen [28]. T-synthase is the only enzyme that galactosylates the Tn antigen (GalNAc $\alpha 1-S e r / T h r-R)$ to form core 1 Gal $\beta 1-3 G a l N A c \alpha 1-S e r / T h r$ ( $\mathrm{T}$ antigen) during mucin-type $O$-glycan biosynthesis [29]. Total cell lysate from pooled CRIPSR (clustered regularly interspaced short palindromic repeats) COSMC HRECs revealed a 70\% reduction of Cosmc at the protein level (Figure 4B,C). The FL EMCN and the different mouse truncation mutants were expressed in CRIPSR COSMC and control HRECs constructs to examine the effect of COSMC deletion on protein $\mathrm{O}$-glycosylation (Figure $4 \mathrm{C}$ ). We suspect that the 50k-Da band observed in AdFL and $\operatorname{Ad} \Delta 21-121$ transfected cells is a degradation product.

A

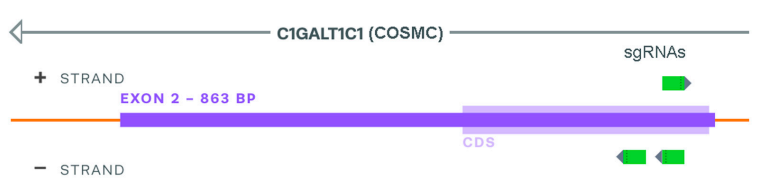

C

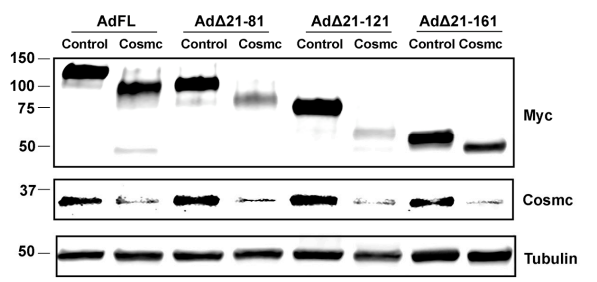

E

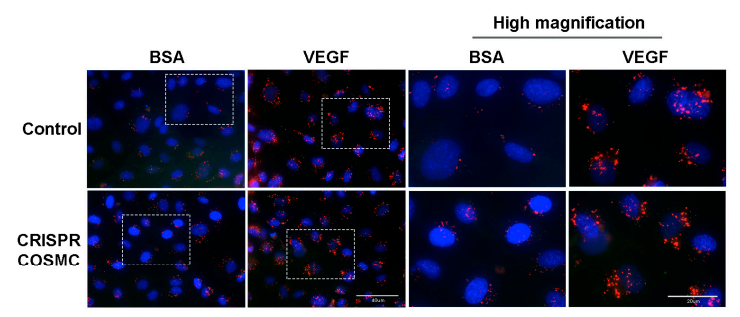

B

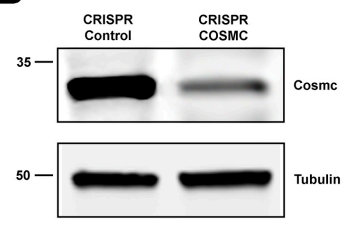

D

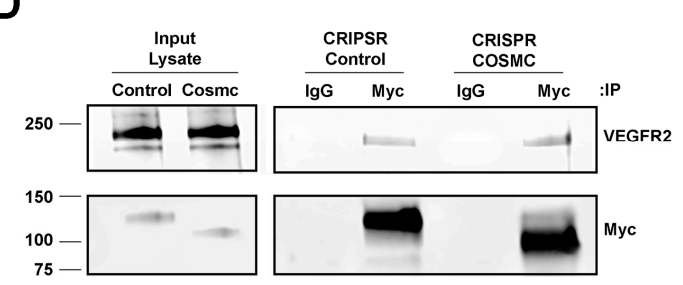

$\mathbf{F}$

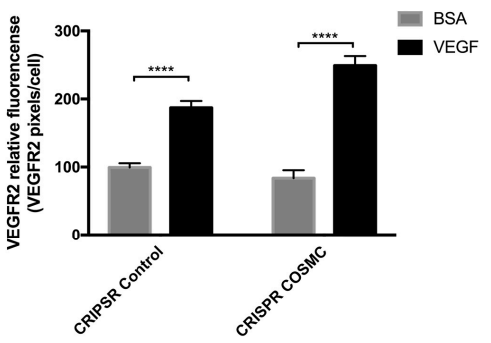

Figure 4. O-glycosylation of EMCN is not required for modulating VEGFR2 signaling. (A) Design of the CRISPR-Cas9 for targeted COSMC knockout in HREC. (B) Whole cell lysates from CRIPSR control and COSMC knockout (CRIPSR Cosmc) were extracted and processed for western blot, which showed approximately $70 \%$ reduction in COSMC protein levels; $n=3$ (C) Whole cell lysate samples were collected $72 \mathrm{~h}$ post-transduction. Molecular weight of the Myc-tagged FL EMCN and EMCN mutants, with and without mucin-type O-glycosylation, were examined by western blot using anti-Myc tag antibody. Protein levels of COSMC revealed a significant reduction of COSMC at the protein level, and $\alpha$-tubulin was used as loading control, confirming the reduction of COSMC. Examination by western blot of FL EMCN, $\triangle 21-81$ EMCN, $\triangle 21-121$ EMCN, and $\triangle 21-161$ EMCN revealed molecular weight reductions of $\sim 30 \mathrm{kDa}, \sim 25 \mathrm{kDa}, \sim 20 \mathrm{kDa}$, and $\sim 10 \mathrm{kDa}$, respectively, consistent with reduced O-glycosylation; $n=3$ (D) The levels of VEGFR2 co-IP'ed with EMCN in CRIPSR control HRECs or COSMC knockout HRECs (CRIPSR Cosmc) and examined by western blot indicate that the lack of $O$-glycosylation did not impact the interaction of EMCN and VEGFR2; $n=3(\mathbf{E}, \mathbf{F})$ To examine VEGFR2 internalization, CRIPSR control HRECs or COSMC knockout HRECs were stimulated with VEGF or BSA and VEGF2 tracked with an antibody that recognizes the VEGFR2 extracellular domain (ECD). 
VEGF stimulated VEGFR2 internalization in both cells, indicating that $O$-glycosylation of EMCN is not necessary for VEGFR2 internalization. Boxes areas in the left-hand panel are shown magnified in the right-hand panels. Lower magnification, scale bar: $40 \mu \mathrm{m}$, higher magnification, scale bar: $20 \mu \mathrm{m}$. (F) The levels of Internalized VEGFR2 were quantified as VEGFR2 pixels divided by the number of cells per images. Data $=$ mean $\pm \mathrm{SEM},{ }^{* * * *} p<0.0001$ by 2 -tail unpaired t-test, $n=6$.

The role of $O$-glycosylation in the interaction with VEGFR2 was examined by co-IP in FL EMCN (Figure 4D). No significant change in VEGFR2 interaction was detected between EMCN with reduced $O$-glycosylation and control EMCN. Since FL mEMCN contains all of the $O$-glycosylation sites, it was not necessary to conduct additional studies to examine the $O$-glycosylation in individual mutants. Moreover, the ability of EMCN with reduced O-glycans to facilitate VEGFR2 internalization was measured utilizing ICC-based VEGFR2 internalization assay. As we have previously shown, loss of EMCN prevented VEGFR2 internalization [21] (Figure S3). Control HREC with non-targeting sgRNA and wildtype EMCN exhibited significant VEGFR2 internalization following VEGF stimulation compared to BSA-treated controls (99.4 \pm 6.3 vs $187.2 \pm 9.9, p<0.001)$, and similarly, CRIPSR COSMC HRECs also showed significant VEGFR2 internalization following VEGF stimulation $(83.7 \pm 11.6 \mathrm{vs}$ $250.2 \pm 13.8, p<0.001$ ) (Figure $4 \mathrm{E}, \mathrm{F}$ ), indicating that $O$-glycosylation of the FL EMCN ECD was not required for VEGFR2 internalization.

\subsection{N-Glycans of the EMCN ECD Are Essential for Its Role in VEGFR2 Function}

The NetNGlyc 1.0 Server (http://www.cbs.dtu.dk/services/NetNGlyc/) predicted five $\mathrm{N}$-glycosylation sites $(28 \mathrm{~N}, 101 \mathrm{~N}, 119 \mathrm{~N}, 127 \mathrm{~N}$, and $131 \mathrm{~N})$ on the mEMCN ECD (Figure $5 \mathrm{~A})$. Whole cell lysates of HRECs expressing FL EMCN, $\triangle 21-81$ EMCN, $\triangle 21-121$ EMCN, and $\triangle 21-161$ EMCN treated with PNGase $\mathrm{F}$ to enzymatically release the $\mathrm{N}$-glycans yielded reduction in molecular weights of the Myc-tagged EMCN mutants following the PNGase F digestion were, as expected, approximately $20 \mathrm{KDa}, 15 \mathrm{KD}, 8 \mathrm{KDa}$, and $0 \mathrm{KDa}$, respectively (Figure 5B). A similar 25-kDa reduction in hEMCN molecular weight was observed after $\mathrm{N}$-glycan removal (Figure S4). Consistent with the lack of any predicted $N$-glycosylation sites, no change in molecular weight was detected for the $\Delta 21-161$ EMCN mutant.

There are two predicted N-glycosylation sites on $\triangle 21-121$ EMCN (Figure 5A), the shortest truncation mutant, which we have shown can interact with and modulate the function of VEGFR2 (Figure 5A). To investigate the role of $\mathrm{N}$-glycans in EMCN function, the two predicted $\mathrm{N}$-glycosylation sites of $\triangle 21-121 \mathrm{EMCN}$ were mutated from asparagine to alanine (N127A and N131A) to generate the $\mathrm{N}$-glycosylation deficient mutant (N-Mut). The interaction with VEGFR2 was completely abolished in the N-Mut compared to the wildtype $\Delta 21-121 \mathrm{EMCN}$ by the cell surface biotinylation/IP/western assay (Figure 5C), demonstrating that $N$-glycosylation of the ECD of $\triangle 21-121 \mathrm{EMCN}$ is required for its interaction with VEGFR2. The effect of $\triangle 21-121$ EMCN or N-Mut on VEGFR2 internalization in HRECs lacking endogenous EMCN was examined and quantified by western blot (Figure 5D,E). Expression of $\triangle 21-121$ EMCN rescued VEGFR2 internalization compared to mCherry, while expression of N-Mut failed to rescue VEGFR2 internalization compared to mCherry. ICC-based VEGFR2 internalization (Figure 5F,G) was consistent with the results above and revealed that the N-Mut failed to rescue the VEGFR2 internalization after VEGF stimulation in HRECs lacking the endogenous EMCN $(98.67 \pm 3.4$ vs $94.25 \pm 12.6, p>0.5)$ (Figure $5 \mathrm{~F}, \mathrm{G}$ ). 
A

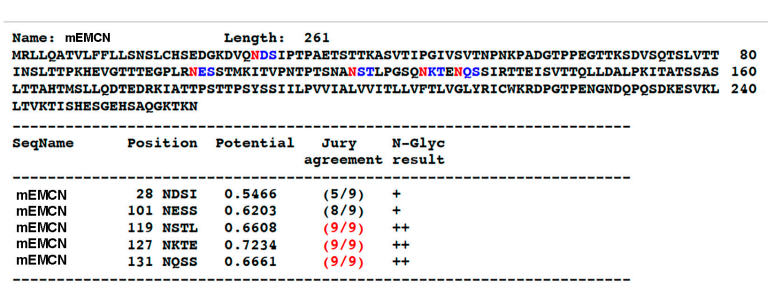

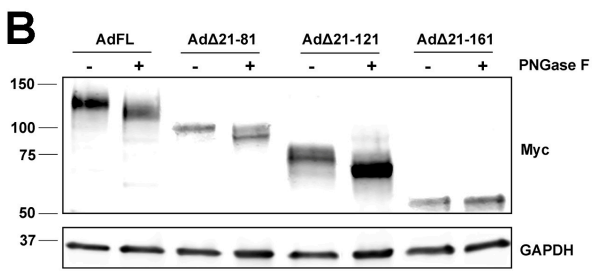

C

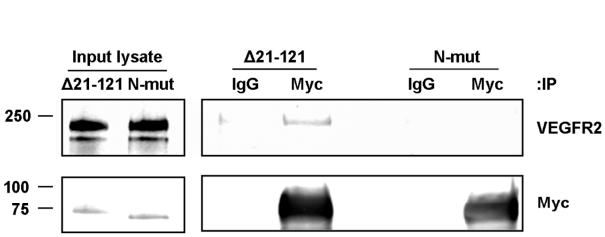

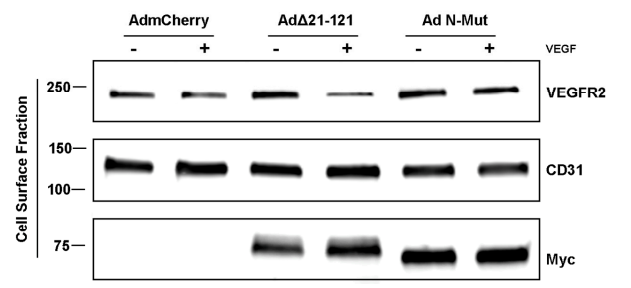

G
$\mathbf{E}$

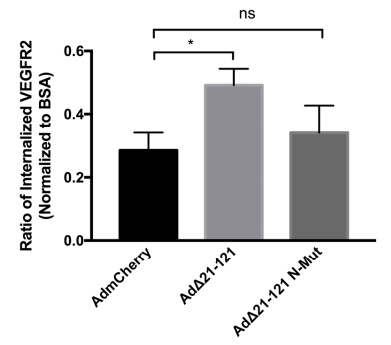

$\mathbf{F}$

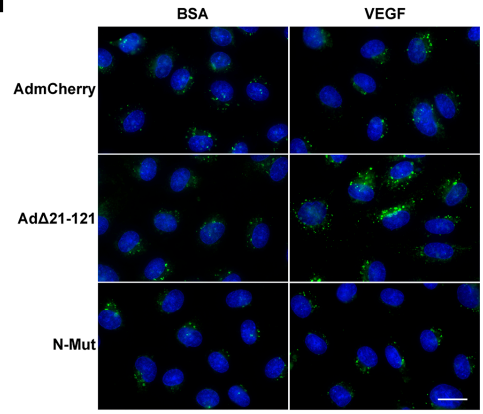

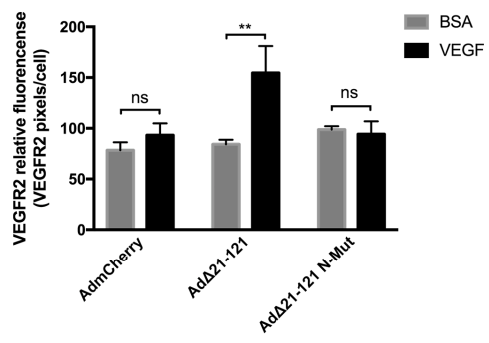

Figure 5. $\mathrm{N}$-glycans on EMCN ECD are essential for EMCN's role in VEGFR2 signaling. (A) Potential $\mathrm{N}$-glycosylation sites (asparagine, N, red) on full-length mEMCN predicted by NetNGlyc 1.0 Server. (B) Molecular weight of FL EMCN, $\Delta 21-81$ EMCN, $\Delta 21-121$ EMCN, and $\triangle 21-161 \mathrm{EMCN}$ with and without PNGase F digestion were examined by western blot; GAPDH was included as loading control. Observed molecular weights are in aligned with predicted sizes. (C) Membrane proteins of HRECs (lacking endogenous hEMCN) expressing Myc-tagged EMCN $\triangle 21-121$ EMCN or $\triangle 21-121$ EMCN with $\mathrm{N}$-glycan sites mutated (N-Mut) were co-IP'ed for using anti-Myc and examined by western blot. The mutant lacking $N$-glycosylation did not bind to VEGFR2. (D) HRECs lacking endogenous hEMCN and expressing either $\triangle 21-121 \mathrm{EMCN}$ or N-Mut were used to examine cell surface expression of VEGFR2 by biotinylation. As seen for the co-IP, the $\Delta 21-121$ lacking $N$-glycosylation was unable to rescue VEGFR2 internalization compared to the normally glycosylated EMCN mutant. (E) Quantification shows reduced VEGFR2 internalization in the absence of $N$-glycosylation. ${ }^{*} p<0.05$ by 2-tail unpaired t-test, $n=4$. (F) Immunocytochemical assay to detect internalized VEGFR2 proteins in HRECs stimulated with VEGF or BSA: Consistent with the findings in Figure 5D,E, $\triangle 21-121 \mathrm{EMCN}$ was able to rescue VEGFR internalization where the $N$-glycosylation mutant was not. Scale bar: $20 \mu \mathrm{m}$. (G) Internalized VEGFR2 was quantified as total VEGFR2-positive pixels divided by the total number of cells per images. Data $=$ mean \pm SEM, ns, not significant, ${ }^{* *} p<0.01$ by 2 -tail unpaired $\mathrm{t}$-test, $n=6$.

\section{Discussion}

We have previously demonstrated that the endothelial-selective glycoprotein EMCN is a key regulator of VEGF signaling. EMCN knockdown using siRNA prevents VEGF-stimulated cell proliferation, migration, and tube formation in HRECs in vitro and significantly impairs retinal vessel development in vivo [30]. In addition, we have shown that EMCN plays a role in these activities by facilitating the internalization of ligand-bound VEGFR2 [21]. Here, we undertook studies to examine the structural features of the EMCN molecule that are required for VEGF-induced ECs functions to further reveal the molecular mechanism by which EMCN regulates VEGF signaling. 
As an important component of the glycocalyx, mucin backbones have heavily glycosylated ectodomains, forming the characteristic bottlebrush molecular structures [26]. Like all mucins, the ECD of mEMCN (amino acids 19-190), which comprises more than 70\% of the molecule (amino acids 19-190), is highly glycosylated. Indeed, EMCN protein core is predicted to account for approximately 27.5 KDa of the molecular weight while the remainder (as measured by western-blot) is due to $O$ and $N$-glycosylation. To determine the role of EMCN ECD, mEMCN truncation mutants were designed according to the predicted glycosylation pattern. Though glycosylation is known to affect the membrane localization and stability of glycoproteins [31], all mutants were glycosylated and detected on the cell surface. FL EMCN, the positive control, rescued VEGF-stimulated EC functions in cells deficient in endogenous hEMCN. mEMCN truncation mutants, $\triangle 21-81$ EMCN, and $\triangle 21-121$ EMCN rescued the VEGF-stimulated angiogenesis functions compared to vehicle construct mCherry (negative control). On the other hand, the shortest mutant $\triangle 21-161$ EMCN failed to facilitate VEGF-mediated ECs functions, indicating that the amino acids 121-190 of the EMCN ECD are sufficient for most, if not all, VEGF-stimulated downstream functions. While the difference between $\triangle 21-121$ EMCN and $\triangle 21-161$ EMCN in their ability to modulate VEGFR2 signaling could suggest an important functional role for amino acids 121-161 of the ECD, our data exclude the domains shared between the two mutants. The $\triangle 21-161$ EMCN mutant includes 28 amino acids of the ECD, the transmembrane and the intracellular domains, which we were unable to express separately. However, these data using $\triangle 21-161$ EMCN indicate that the intracellular domain alone would not be sufficient to rescue VEGF-induced functions.

Upon binding VEGF, VEGFR2 is internalized via the clathrin-mediated pathway [32] or macropinocytosis [9] and is then either recycled back to the plasma membrane or targeted to the proteasome for lysosomal degradation. Clathrin-independent endocytosis, like endophilin-A2 dependent internalization, has been reported [33]. VEGFR2 signaling has been shown to continue following endocytosis, which is reported to be necessary for successful VEGF signal transduction and activation of ERK1/2 in endothelium [34]. Thus, modulating VEGR2 endocytosis can greatly impact VEGF-induced functions. For example, silencing clathrin-associated sorting protein, Dab2, impairs VEGFR2 internalization and reduces downstream signal transduction [35]. Regulator of calcineurin 1.4 (RCAN 1.4) regulates agonist-stimulated VEGFR-2 internalization, modulating VEGF-stimulated endothelial cell migration by establishing endothelial cell polarity [36]. VEGFR2 associates with other receptors and/or glycoproteins such as neuropilin-1 (NRP1), heparin sulfate proteoglycans, and endoglin [7,37]. NRP1, a VEGFR2 co-receptor, interacts with VEGFR2 and is internalized with VEGFR2 to guide its recycling [4]. EMCN interacts with VEGFR2 and is essential for its internalization, but unlike NRP1, EMCN itself is not internalized along with VEGFR2 following VEGF stimulation [21]. Here, we show that $\triangle 21-121$ EMCN interacts with VEGFR2 and is sufficient to support both the interaction of EMCN with VEGFR2 as well as VEGFR2 internalization. X-ray crystallographic analysis of VEGFR2 suggests that its ECD extends around $200 \AA$ from the cell surface $[38,39]$. While the structure of EMCN has not been characterized, it is reasonable to predict that the high level of glycosylation causes EMCN to project rigidly from the cell surface, similar to other mucins. Assuming 3.5 A per amino acid, the full-length ECD of EMCN is estimated to be roughly $600 \AA[40,41]$, whereas $\Delta 121-121$ EMCN, the smallest mutant that can rescue VEGF-induced functions, would be estimated to be approximately $300 \AA$. In contrast, the $\Delta 21-161$ mutant that was unable to rescue, would be about $175 \AA$, possibly too short to interact optimally with VEGFR2.

Mucin-type O-linked glycosylation is so important in many biological processes [42] since C1GalT1 (T synthase) is the only enzyme that glycosylates the Tn antigen (GalNAc $\alpha 1-S e r / T h r-R)$ to form core 1 Gal $\beta 1-3 G$ alNAc $\alpha 1-S e r / T h r$ (T antigen) [43]. The absence of the required chaperone, Cosmc, results in immature and truncated $O$-glycans that lack biological function $[28,44]$. In order to study the role of EMCN O-glycans in VEGFR2-EMCN interaction and VEGFR2 internalization, we generated Cosmc knockout HRECs using CRISPR/Cas 9 and showed that mucin O-glycosylation contributes approximately $30 \mathrm{KDa}$ to the molecular weight of the mouse EMCN. As there are more than 50 predicted $O$-glycosylation sites on the EMCN ECD, this indicates that, while mucin-type 
$O$-glycans are abundant, at an average molecular weight of approximately 600 their chains are relatively short. Importantly, in spite of their abundance, co-IP data showed that $O$-glycan chains on EMCN are not necessary for EMCN-VEGFR2 interaction. Consistent with these findings, an immunocytochemistry-based assay showed that impaired $O$-glycosylation on EMCN did not prevent VEGF-induced VEGFR2 internalization.

We next turned our attention to the possible contribution of $\mathrm{N}$-glycans. $\mathrm{N}$-glycan precursors are synthesized in the endoplasmic reticulum as a branched structure on a lipid anchor. $\mathrm{N}$-glycosidase $\mathrm{F}$ (PNGase F) cleaves the linkage between the asparagine residue and innermost $\mathrm{N}$-acetylglucosamine (GlcNAc) of nearly all N-glycans [45]. An approximate $20 \mathrm{KDa}$ reduction in molecular weight was observed in hEMCN following PNGase F-induced cleavage of $\mathrm{N}$-glycans compared to control, suggesting that, with an approximate molecular weight of $4000 \mathrm{Da}$, the $\mathrm{N}$-glycans on EMCN are relatively long and/or highly branched. $\mathrm{N}$-glycans are known to facilitate proper folding of nascent proteins; to enhance the protein solubility or polarity; and, most relevant to our findings, to mediate protein association in receptor/ligand complexes or sugar-specific binding proteins in the plasma membrane that mediate receptor endocytosis and trafficking [46-50]. For example, galectin-3 binds to $N$-linked glycans on CD146/MCAM (Melanoma Cell Adhesion Molecule) and induces CD146 dimerization and subsequent activation of AKT (Protein kinase B) signaling [51]. Galectin-1 (Gal1) delivers angiogenic signals through a glycosylation-dependent pathway involving context-dependent remodeling of complex $\mathrm{N}$-glycans. Targeting the Gal1-N-Glycan could overcome resistance to anti-VEGF [52]. Our data indicate that $N$-glycans on EMCN are crucial in the EMCN-VEGFR2 interaction and internalization.

VEGF induces both angiogenesis and vascular permeability. Angiogenesis is rate limiting for tumor growth and metastasis and is a devastating component of a number of ocular pathologies such as proliferative diabetic retinopathy and wet age-related macular degeneration. While VEGFR2 is widely expressed, not only by the endothelium but also by a variety of epithelial cells and neurons [53], EMCN is specifically expressed by endothelial cells, particularly in proliferating capillaries [29]. Accordingly, EMCN represents an endothelial-specific target for modulating VEGF responses, so a deeper mechanistic understanding of its role in VEGF signaling presented here is essential for future translational development of EMCN as a potential therapeutic target.

Supplementary Materials: The following are available online at http://www.mdpi.com/2073-4409/9/6/1413/s1, Figure S1: Cell surface expression of mEMCN mutants: Indicated EMCN mutants were expressed in HREC, and cell surface expression was examined using biotinylation followed by western blotting, Figure S2: FL EMCN interacts with VEGFR2, Figure S3: EMCN knockdown prevents VEGFR2 internalization, Figure S4: $N$-glycosylation in human EMCN.

Author Contributions: Z.H., K.L.S.-T., and I.C. performed the research; M.E.L., M.S.-G., Y.-S.N., and P.A. provided critical discussion and technical help for the experiments; Z.H., M.S.-G., Y.-S.N., P.A., and P.A.D. designed the research; Z.H. analyzed the data and wrote the first draft of the manuscript; K.L.S.-T., I.C., M.E.L., M.S.-G., Y.-S.N., and P.A. reviewed the manuscript; and P.A.D. directed the study, interpreted results with Z.H., and did the major editing of the manuscript. All authors have read and agreed to the published version of the manuscript.

Acknowledgments: This work was supported by NIH/NEI R01 EY026539 (to P.A.D.), NIH/NEI P30 EY003790, the VitreoRetinal Surgery Foundation Research Fellowship (to Z.H.), and the Knights Templar Pediatric Ophthalmology Career-Starter Grant (to Z.H.).

Conflicts of Interest: The authors declare no conflict of interest.

\section{References}

1. Nowak-Sliwinska, P.; Alitalo, K.; Allen, E.; Anisimov, A.; Aplin, A.C.; Auerbach, R.; Augustin, H.G.; Bates, D.O.; van Beijnum, J.R.; Bender, R.H.F.; et al. Consensus guidelines for the use and interpretation of angiogenesis assays. Angiogenesis 2018, 21, 425-532. [CrossRef] [PubMed]

2. Bikfalvi, A. History and conceptual developments in vascular biology and angiogenesis research: A personal view. Angiogenesis 2017, 20, 463-478. [CrossRef] [PubMed] 
3. Griffioen, A.W.; Molema, G. Angiogenesis: Potentials for pharmacologic intervention in the treatment of cancer, cardiovascular diseases, and chronic inflammation. Pharmacol. Rev. 2000, 52, 237-268. [PubMed]

4. Simons, M.; Gordon, E.; Claesson-Welsh, L. Mechanisms and regulation of endothelial VEGF receptor signalling. Nat. Rev. Mol. Cell Biol. 2016, 17, 611-625. [CrossRef]

5. Gutiérrez-González, A.; Aguilera-Montilla, N.; Ugarte-Berzal, E.; Bailón, E.; Cerro-Pardo, I.; Sánchez-Maroto, C.; García-Campillo, L.; García-Marco, J.A.; García-Pardo, A. alpha4beta1 integrin associates with VEGFR2 in CLL cells and contributes to VEGF binding and intracellular signaling. Blood Adv. 2019, 3, 2144-2148. [CrossRef]

6. Clegg, L.W.; Mac Gabhann, F. Site-Specific Phosphorylation of VEGFR2 Is Mediated by Receptor Trafficking: Insights from a Computational Model. PLoS Comput. Biol. 2015, 11, e1004158. [CrossRef]

7. Tian, H.; Huang, J.J.; Golzio, C.; Gao, X.; Hector-Greene, M.; Katsanis, N.; Blobe, G.C. Endoglin interacts with VEGFR2 to promote angiogenesis. FASEB J. 2018, 32, 2934-2949. [CrossRef]

8. Salikhova, A.; Wang, L.; Lanahan, A.A.; Liu, M.; Simons, M.; Leenders, W.P.J.; Mukhopadhyay, D.; Horowitz, A. Vascular endothelial growth factor and semaphorin induce neuropilin-1 endocytosis via separate pathways. Circ. Res. 2008, 103, e71-e79. [CrossRef]

9. Ballmer-Hofer, K.; Andersson, A.E.; Ratcliffe, L.E.; Berger, P. Neuropilin-1 promotes VEGFR-2 trafficking through Rab11 vesicles thereby specifying signal output. Blood 2011, 118, 816-826. [CrossRef]

10. Basagiannis, D.; Zografou, S.; Murphy, C.; Fotsis, T.; Morbidelli, L.; Ziche, M.; Bleck, C.; Mercer, J.; Christoforidis, S. VEGF induces signalling and angiogenesis by directing VEGFR2 internalisation through macropinocytosis. J. Cell Sci. 2016, 129, 4091-4104. [CrossRef]

11. Basagiannis, D.; Christoforidis, S. Constitutive Endocytosis of VEGFR2 Protects the Receptor against Shedding. J. Biol. Chem. 2016, 291, 16892-16903. [CrossRef] [PubMed]

12. Lin, Y.-C.; Chao, T.-Y.; Yeh, C.-T.; Roffler, S.R.; Kannagi, R.; Yang, R.-B. Endothelial SCUBE2 interacts with VEGFR2 and regulates VEGF-induced angiogenesis. Arterioscler. Thromb. Vasc. Biol. 2017, 37, 144-155. [CrossRef] [PubMed]

13. Jiang, T.; Zhuang, J.; Duan, H.; Luo, Y.; Zeng, Q.; Fan, K.; Yan, H.; Lu, D.; Ye, Z.; Hao, J.; et al. CD146 is a coreceptor for VEGFR-2 in tumor angiogenesis. Blood 2012, 120, 2330-2339. [CrossRef] [PubMed]

14. Khayati, F.; Pérez-Cano, L.; Maouche, K.; Sadoux, A.; Boutalbi, Z.; Podgorniak, M.-P.; Maskos, U.; Setterblad, N.; Janin, A.; Calvo, F.; et al. EMMPRIN/CD147 is a novel coreceptor of VEGFR-2 mediating its activation by VEGF. Oncotarget 2015, 6, 9766-9780. [CrossRef] [PubMed]

15. Herkenne, S.; Paques, C.; Nivelles, O.; Lion, M.; Bajou, K.; Pollenus, T.; Fontaine, M.; Carmeliet, P.; Martial, J.A.; Nguyen, N.-Q.-N.; et al. The interaction of UPAR with VEGFR2 promotes VEGF-induced angiogenesis. Sci. Signal 2015, 8, ra117. [CrossRef]

16. Zhu, W.; Shi, D.S.; Winter, J.M.; Rich, B.E.; Tong, Z.; Sorensen, L.K.; Zhao, H.; Huang, Y.; Tai, Z.; Mleynek, T.M.; et al. Small GTPase ARF6 controls VEGFR2 trafficking and signaling in diabetic retinopathy. J. Clin. Invest. 2017, 127, 4569-4582. [CrossRef]

17. Uchimido, R.; Schmidt, E.P.; Shapiro, N.I. The glycocalyx: A novel diagnostic and therapeutic target in sepsis. Crit. Care 2019, 23, 16. [CrossRef]

18. Desideri, S.; Onions, K.L.; Baker, S.L.; Gamez, M.; El Hegni, H.; Hussien, E.; Russell, A.; Satchell, S.C.; Foster, R.R. Endothelial glycocalyx restoration by growth factors in diabetic nephropathy. Biorheology 2019, 56, 163-179. [CrossRef]

19. Rai, S.; Nejadhamzeeigilani, Z.; Gutowski, N.J.; Whatmore, J.L. Loss of the endothelial glycocalyx is associated with increased E-selectin mediated adhesion of lung tumour cells to the brain microvascular endothelium. J. Exp. Clin. Cancer Res. 2015, 34, 105. [CrossRef]

20. Gorsi, B.; Liu, F.; Ma, X.; Chico, T.J.A.; Shrinivasan, A.; Kramer, K.L.; Bridges, E.; Monteiro, R.; Harris, A.L.; Patient, R.; et al. The heparan sulfate editing enzyme Sulf1 plays a novel role in zebrafish VegfA mediated arterial venous identity. Angiogenesis 2014, 17, 77-91. [CrossRef]

21. LeBlanc, M.E.; Saez-Torres, K.L.; Cano, I.; Hu, Z.; Saint-Geniez, M.; Ng, Y.-S.; D’Amore, P.A. Glycocalyx regulation of vascular endothelial growth factor receptor 2 activity. FASEB J. 2019, 33, 9362-9373. [CrossRef] [PubMed]

22. Chiu, W.-C.; Lin, J.-Y.; Lee, T.-S.; You, L.-R.; Chiang, A.-N. beta(2)-glycoprotein I inhibits VEGF-induced endothelial cell growth and migration via suppressing phosphorylation of VEGFR2, ERK1/2, and Akt. Mol. Cell. Biochem. 2013, 372, 9-15. [CrossRef] [PubMed] 
23. Imamaki, R.; Ogawa, K.; Kizuka, Y.; Komi, Y.; Kojima, S.; Kotani, N.; Honke, K.; Honda, T.; Taniguchi, N.; Kitazume, S. Glycosylation controls cooperative PECAM-VEGFR2-beta3 integrin functions at the endothelial surface for tumor angiogenesis. Oncogene 2018, 37, 4287-4299. [CrossRef] [PubMed]

24. Strzyz, P. Bend it like glycocalyx. Nat. Rev. Mol. Cell. Biol. 2019, 20, 388. [CrossRef] [PubMed]

25. Singh, P.K.; Hollingsworth, M.A. Cell surface-associated mucins in signal transduction. Trends Cell Biol. 2006, 16, 467-476. [CrossRef] [PubMed]

26. Van Putten, J.P.M.; Strijbis, K. Transmembrane Mucins: Signaling Receptors at the Intersection of Inflammation and Cancer. J. Innate Immun. 2017, 9, 281-299. [CrossRef] [PubMed]

27. Shurer, C.R.; Kuo, J.C.-H.; Monét Roberts, L.; Gandhi, J.G.; Colville, M.J.; Enoki, T.A.; Pan, H.; Su, J.; Noble, J.M.; Hollander, M.J.; et al. Physical Principles of Membrane Shape Regulation by the Glycocalyx. Cell 2019, 177, 1757.e1721-1770.e1721. [CrossRef]

28. Wang, Y.; Ju, T.; Ding, X.; Xia, B.; Wang, W.; Xia, L.; He, M.; Cummings, R.D. Cosmc is an essential chaperone for correct protein O-glycosylation. Proc. Natl. Acad. Sci. USA 2010, 107, 9228-9233. [CrossRef] [PubMed]

29. Abdel-Rahman, M.H.; Pilarski, R.; Ezzat, S.; Sexton, J.; Davidorf, F.H. Cancer family history characterization in an unselected cohort of 121 patients with uveal melanoma. Fam. Cancer 2010, 9, 431-438. [CrossRef]

30. Hofmann, B.T.; Schlüter, L.; Lange, P.; Mercanoglu, B.; Ewald, F.; Fölster, A.; Picksak, A.-S.; Harder, S.; El Gammal, A.T.; Grupp, K.; et al. COSMC knockdown mediated aberrant O-glycosylation promotes oncogenic properties in pancreatic cancer. Mol. Cancer 2015, 14, 109. [CrossRef]

31. Park-Windhol, C.; Ng, Y.S.; Yang, J.; Primo, V.; Saint-Geniez, M.; D’Amore, P.A. Endomucin inhibits VEGF-induced endothelial cell migration, growth, and morphogenesis by modulating VEGFR2 signaling. Sci. Rep. 2017, 7, 17138. [CrossRef]

32. Weng, T.-Y.; Chiu, W.-T.; Liu, H.-S.; Cheng, H.-C.; Shen, M.-R.; Mount, D.B.; Chou, C.-Y. Glycosylation regulates the function and membrane localization of KCC4. Biochim. Biophys. Acta 2013, 1833, 1133-1146. [CrossRef]

33. Kofler, N.; Corti, F.; Rivera-Molina, F.; Deng, Y.; Toomre, D.; Simons, M. The Rab-effector protein RABEP2 regulates endosomal trafficking to mediate vascular endothelial growth factor receptor-2 (VEGFR2)-dependent signaling. J. Biol. Chem. 2018, 293, 4805-4817. [CrossRef] [PubMed]

34. Genet, G.; Boyé, K.; Mathivet, T.; Ola, R.; Zhang, F.; Dubrac, A.; Li, J.; Genet, N.; Geraldo, L.H.; Benedetti, L.; et al. Endophilin-A2 dependent VEGFR2 endocytosis promotes sprouting angiogenesis. Nat. Commun. 2019, 10, 2350. [CrossRef] [PubMed]

35. Gourlaouen, M.; Welti, J.C.; Vasudev, N.S.; Reynolds, A.R. Essential role for endocytosis in the growth factor-stimulated activation of ERK1/2 in endothelial cells. J. Biol. Chem. 2013, 288, 7467-7480. [CrossRef] [PubMed]

36. Nakayama, M.; Nakayama, A.; van Lessen, M.; Yamamoto, H.; Hoffmann, S.; Drexler, H.C.A.; Itoh, N.; Hirose, T.; Breier, G.; Vestweber, D.; et al. Spatial regulation of VEGF receptor endocytosis in angiogenesis. Nat. Cell Biol. 2013, 15, 249-260. [CrossRef] [PubMed]

37. Alghanem, A.F.; Wilkinson, E.L.; Emmett, M.S.; Aljasir, M.A.; Holmes, K.; Rothermel, B.A.; Simms, V.A.; Heath, V.L.; Cross, M.J. RCAN1.4 regulates VEGFR-2 internalisation, cell polarity and migration in human microvascular endothelial cells. Angiogenesis 2017, 20, 341-358. [CrossRef] [PubMed]

38. Panigrahy, D.; Adini, I.; Mamluk, R.; Levonyak, N.; Bruns, C.J.; D’Amore, P.A.; Klagsbrun, M.; Bielenberg, D.R. Regulation of soluble neuropilin 1, an endogenous angiogenesis inhibitor, in liver development and regeneration. Pathology 2014, 46, 416-423. [CrossRef]

39. Yuzawa, S.; Opatowsky, Y.; Zhang, Z.; Mandiyan, V.; Lax, I.; Schlessinger, J. Structural basis for activation of the receptor tyrosine kinase KIT by stem cell factor. Cell 2007, 130, 323-334. [CrossRef]

40. Brozzo, M.S.; Bjelić, S.; Kisko, K.; Schleier, T.; Leppänen, V.-M.; Alitalo, K.; Winkler, F.K.; Ballmer-Hofer, K. Thermodynamic and structural description of allosterically regulated VEGFR-2 dimerization. Blood 2012, 119, 1781-1788. [CrossRef]

41. Adhikari, B.; Cheng, J. Protein Residue Contacts and Prediction Methods. Methods Mol. Biol. 2016, 1415, 463-476. [PubMed]

42. Ainavarapu, S.R.K.; Brujic, J.; Huang, H.H.; Wiita, A.P.; Lu, H.; Li, L.; Walther, K.A.; Carrion-Vazquez, M.; Li, H.; Fernandez, J.M. Contour length and refolding rate of a small protein controlled by engineered disulfide bonds. Biophys. J. 2007, 92, 225-233. [CrossRef] [PubMed] 
43. Hang, H.C.; Bertozzi, C.R. The chemistry and biology of mucin-type O-linked glycosylation. Bioorg. Med. Chem. 2005, 13, 5021-5034. [CrossRef] [PubMed]

44. Ju, T.; Cummings, R.D. Protein glycosylation: Chaperone mutation in Tn syndrome. Nature 2005, 437, 1252. [CrossRef] [PubMed]

45. Huang, Y.; Orlando, R. Kinetics of N-Glycan Release from Human Immunoglobulin G (IgG) by PNGase F: All Glycans Are Not Created Equal. J. Biomol. Tech. 2017, 28, 150-157. [CrossRef] [PubMed]

46. Bieberich, E. Synthesis, Processing, and Function of N-glycans in N-glycoproteins. Adv. Neurobiol. 2014, 9 , 47-70. [PubMed]

47. Lajoie, P.; Nabi, I.R. Lipid rafts, caveolae, and their endocytosis. Int. Rev. Cell Mol. Biol. 2010, 282, $135-163$.

48. Lajoie, P.; Goetz, J.G.; Dennis, J.W.; Nabi, I.R. Lattices, rafts, and scaffolds: Domain regulation of receptor signaling at the plasma membrane. J. Cell Biol. 2009, 185, 381-385. [CrossRef]

49. Dennis, J.W.; Nabi, I.R.; Demetriou, M. Metabolism, cell surface organization, and disease. Cell 2009, 139, 1229-1241. [CrossRef]

50. Boscher, C.; Dennis, J.W.; Nabi, I.R. Glycosylation, galectins and cellular signaling. Curr. Opin. Cell Biol. 2011, 23, 383-392. [CrossRef]

51. Colomb, F.; Wang, W.; Simpson, D.; Zafar, M.; Beynon, R.; Rhodes, J.M.; Yu, L.-G. Galectin-3 interacts with the cell-surface glycoprotein CD146 (MCAM, MUC18) and induces secretion of metastasis-promoting cytokines from vascular endothelial cells. J. Biol. Chem. 2017, 292, 8381-8389. [CrossRef] [PubMed]

52. Croci, D.O.; Cerliani, J.P.; Dalotto-Moreno, T.; Méndez-Huergo, S.P.; Mascanfroni, I.D.; Dergan-Dylon, S.; Toscano, M.A.; Caramelo, J.J.; García-Vallejo, J.J.; Ouyang, J.; et al. Glycosylation-dependent lectin-receptor interactions preserve angiogenesis in anti-VEGF refractory tumors. Cell 2014, 156, 744-758. [CrossRef] [PubMed]

53. Marquez-Exposito, L.; Lavoz, C.; Rodrigues-Diez, R.R.; Rayego-Mateos, S.; Orejudo, M.; Cantero-Navarro, E.; Ortiz, A.; Egido, J.; Selgas, R.; Mezzano, S.; et al. Gremlin Regulates Tubular Epithelial to Mesenchymal Transition via VEGFR2: Potential Role in Renal Fibrosis. Front. Pharmacol. 2018, 9, 1195. [CrossRef] [PubMed] 